\title{
STATARY BEHAVIOR IN NOMADIC COLONIES OF ARMY ANTS: \\ THE EFFECT OF OVERFEEDING
}

\author{
By Howard Topoff, Aron Rothstein*, Susan Pujdak, and \\ Tina DAhLSTROM** \\ Department of Psychology, Hunter College of CUNY, New York, \\ N.Y. 10021, and The American Museum of Natural History
}

\section{INTRODUCTION}

Nearctic colonies of the army ant Neivamyrmex nigrescens Cresson (subfamily Ecitoninae) exhibit behavioral cycles consisting of alternating nomadic and statary phases. During the statary phase, a colony remains at the same nesting site and forages irregularly for food. The nomadic phase, by contrast, is characterized by night-long raids and frequent emigrations to new bivouacs. According to Schneirla $(1957,1958)$, the nomadic phase is triggered by stimulation arising from newly-eclosed callows, and is subsequently maintained by comparable excitation from the developing larvae. Experimental support for brood-stimulation theory stems from studies showing: (1) an abrupt reduction in nomadism after removing a portion of a larval brood (Schneirla and Brown, 1950); and (2) the eclosion of a pupal brood (in the absence of newlyhatched larvae) is indeed sufficient to initiate a nomadic phase (Topoff et al., 1980a). Recent studies have suggested, however, that brood stimulation may in turn depend on the degree of brood satiation. Thus, in a preliminary field study involving food augmentation, Mirenda et al. (in press) was able to halt the occurrence of emigrations during a portion of the nomadic phase in colonies of $N$. nigrescens. This was followed by more prolonged laboratory studies (Topoff and Mirenda, $1980 \mathrm{a}, \mathrm{b}$ ) showing that the frequency and direction of nomadic emigrations are indeed influenced by the amount and location of food.

This paper reports findings from our continued studies of food augmentation for colonies of $N$. nigrescens. In previous studies, larval stimulation was reduced by artificially feeding colonies early in the nomadic phase, after callow eclosion. Because an additional

*Department of Biology, City College of CUNY, New York, N.Y. 10031

**Department of Zoology, University of California, Riverside, CA 92521 
goal of the present study was to reduce callow stimulation and thereby delay the onset of the nomadic phase, overfeeding commenced late in the statary period. For the first colony, emigrations were delayed approximately 6 days. In the second overfed colony, we were able to virtually eliminate the nomadic phase, together with all associated patterns of raiding and emigration behavior.

\section{Methods AND Procedures}

This study was conducted during July and August, 1980, in a desert-grassland habitat, $8 \mathrm{~km}$ east of Portal, Arizona. The site was chosen because the pavement-like substrate and patchy vegetation provided us with an excellent view of the ants' raiding and emigration activities. Surface soil temperatures averaged $50^{\circ} \mathrm{C}$ at $1500 \mathrm{hr}$ (MST) and $17^{\circ} \mathrm{C}$ at $0200 \mathrm{hr}$ throughout the summer (Mirenda et al. 1980). As a result of the severe daytime temperatures and aridity, colonies of $N$. nigrescens were usually active on the surface only between 1900-0500 hr.

Colonies were located by walking through the study area with gasoline lanterns or miner's cap lamps. Colony no. 1 was found on July 11 , at the end of a nomadic phase, and observed nightly throughout its next statary period. During the subsequent nomadic phase, the colony was estimated to contain approximately 80,000 adults and 50,000 larvae. Colony no. 2 was collected on July 14, during its last nomadic emigration, and maintained in the laboratory (see Topoff et al. 1980b for details of the rearing procedure) until the pupal brood was fully pigmented. Prior to release in the field, the colony was culled to contain 4,000 adults and 4,000 pupae. By the next nomadic phase, approximately 4,500 larvae were also present in the colony. This small colony size was chosen for two reasons: (1) to increase our ability to appreciably overfeed the colony; and (2) a laboratory colony of comparable size had previously been released without food supplementation, as part of a study designed to show that laboratory rearing and population reduction do not alter qualitative aspects of nomadic behavior. This colony could therefore serve as a convenient control for our artificially-fed colony.

Food for both experimental colonies consisted of adult and brood individuals of the myrmicine ant Novomessor cockerelli, and workers of the termite genus Gnathamitermes. To collect Novo- 
messor brood we made use of the panic-alarm behavior that this prey species exhibits when raided by army ants. Accordingly, we released several hundred adult $N$. nigrescens into the nest entrance of Novomessor, and aspirated the larvae and pupae that were removed from the nest by their own adult workers. Whenever colonies were artificially fed, food was given at the start of raiding in the evening, while the column was within $2 \mathrm{~m}$ from their bivouac. If columns emerged from more than one exit hole, booty was placed at the front of each ant column.

\section{RESULTS}

The raiding and emigration activities of colony no. 1 are summarized in Table 1. This colony was found on July 11, late in its nomadic phase. It became statary on July 13, after settling into a kangaroo rat mound (Dipodomys spectabilis). On the third statary night, the colony conducted a 3-m long shift to the other side of the mound. A statary shift differs from a nomadic emigration in that it is neither preceded nor followed by raiding. It consists instead of a single, unbranched column, and is presumably caused by a disturbance at the old site. For the next 13 statary days, the colony remained at the same bivouac, and staged either brief $(1-3 \mathrm{hr})$ or no predatory raids. On statary day 17 , however, the colony conducted a longer shift to an adjacent mound. During the move, we observed that all of the pupae were deeply pigmented, and that a few callows were being transported by mature adults to the new site. As a result of detecting the onset of eclosion, we started artificial feeding of the colony on the next night (July 30), and continued to supply food for a total of six consecutive nights (Table 1).

Each evening, a basal column appeared on the surface shortly after sunset (1800-1900 hr). As soon as the ants contacted the food, the process of mass recruitment resulted in a sharp increase in ant traffic out of the nest. On the days of heaviest feeding, when more than $30 \mathrm{~g}$ of booty were provided, the army ants required several hours to transport it back to the bivouac. The colony occasionally put out additional raiding columns later each night, but all captured booty was promptly brought back to the original bivouac, and no emigrations occurred. On the afternoon of August 5, the study area received $14 \mathrm{~mm}$ of rainfall between $1400-1550 \mathrm{hr}$. The overcast sky, coupled with cool temperatures late in the afternoon, enabled the 
Table 1. Activity schedule for Neivamyrmex nigrescens colony no. 1

\begin{tabular}{|c|c|c|c|c|}
\hline \multirow[b]{2}{*}{ Date } & \multicolumn{2}{|c|}{ Activity } & \multirow{2}{*}{$\begin{array}{c}\text { Food } \\
\text { Provided (g) }\end{array}$} & \multirow{2}{*}{$\begin{array}{l}\text { Proposed } \\
\text { Phase-Day }\end{array}$} \\
\hline & Raid & Emigrate & & \\
\hline $7 / 11$ & + & + & - & $\mathrm{N}-?$ \\
\hline $7 / 12$ & + & + & - & $\mathrm{N}-?$ \\
\hline $7 / 13$ & + & - & - & S-1 \\
\hline $7 / 14$ & + & - & - & S-2 \\
\hline $7 / 15$ & - & ss* & - & S-3 \\
\hline $7 / 16$ & + & - & - & $S-4$ \\
\hline $7 / 17$ & + & - & - & S-5 \\
\hline $7 / 18$ & + & - & - & S-6 \\
\hline $7 / 19$ & + & - & - & S-7. \\
\hline $7 / 20$ & - & - & - & S-8 \\
\hline $7 / 21$ & - & - & - & S-9 \\
\hline $7 / 22$ & - & - & - & S-10 \\
\hline $7 / 23$ & + & - & - & S-11 \\
\hline $7 / 24$ & - & - & - & S-12 \\
\hline $7 / 25$ & - & - & - & S-13 \\
\hline $7 / 26$ & - & - & - & S-14 \\
\hline $7 / 27$ & - & - & - & S-15 \\
\hline $7 / 28$ & - & - & - & S-16 \\
\hline $7 / 29$ & - & ss* & - & S-17 \\
\hline $7 / 30$ & + & - & 9.1 & S-18 \\
\hline $7 / 31$ & + & - & 34.7 & $\mathrm{~N}-1$ \\
\hline $8 / 1$ & + & - & 18.5 & $\mathrm{~N}-2$ \\
\hline $8 / 2$ & + & - & 32.6 & $\mathrm{~N}-3$ \\
\hline $8 / 3$ & + & - & 17.6 & N-4 \\
\hline $8 / 4$ & + & - & 31.6 & N-5 \\
\hline $8 / 5$ & + & + & - & N-6 \\
\hline $8 / 6$ & + & + & - & $\mathrm{N}-7$ \\
\hline $8 / 7$ & + & + & - & N-8 \\
\hline $8 / 8$ & + & + & - & N-9 \\
\hline $8 / 9$ & + & - & - & $\mathrm{N}-10$ \\
\hline $8 / 10$ & + & + & - & $\mathrm{N}-11$ \\
\hline $8 / 11$ & + & - & - & $\mathrm{N}-12$ \\
\hline $8 / 12$ & + & + & - & $\mathrm{N}-13$ \\
\hline $8 / 13$ & + & + & - & $\mathrm{N}-14$ \\
\hline $8 / 14$ & + & - & - & S-1 \\
\hline $8 / 15$ & + & - & - & S-2 \\
\hline $8 / 16$ & + & - & - & S-3 \\
\hline $8 / 17$ & + & - & - & S-4 \\
\hline $8 / 18$ & + & - & - & S-5 \\
\hline $8 / 19$ & - & - & - & S-6 \\
\hline $8 / 20$ & + & - & - & S-7 \\
\hline $8 / 21$ & - & - & - & S-8 \\
\hline $8 / 22$ & + & - & - & S-9 \\
\hline
\end{tabular}

*statary shift 
colony to begin raiding earlier than usual. Thus, although we arrived at the site by $1800 \mathrm{hr}$, a long $(60 \mathrm{~m})$ emigration was already in progress. Given the large size of the colony, we decided to terminate food-augmentation. The colony remained nomadic for the next nine days, during which time it emigrated on six nights.

In order to determine whether we had been successful in delaying the onset of the nomadic phase, three independent types of evidence were analyzed: (1) phase length: (2) callow pigmentation; and (3) larval size. Collectively, our data indicate that the nomadic phase was indeed delayed for 4-8 days.

Phase Length: Because the colony was temporally anchored, July 13 can be considered the first statary day, August 5 the first nomadic day. Thus, the statary interval becomes 23 days (Table 1). According to Mirenda and Topoff (1980), the range of statary-phase duration for $N$. nigrescens in the same study area is 15-19 days, with a modal length of 16 days. This suggests that the minimum delay in nomadic onset for our colony was 4 days. If we use instead Mirenda and Topoff's modal duration, the delay is calculated as 7 days.

Callow pigmentation: Newly eclosed callows of $N$. nigrescens are yellow and acquire adult-like pigmentation between 7-12 days. Several hundred callows were collected from the colony during its first emigration on August 5, and compared with preserved samples collected daily from nomadic colonies in previous years. Although this form of visual comparison can not always pinpoint the exact post-eclosion day, callows from the artificially-fed colony were substantially more pigmented than those typically collected from other colonies on the first nomadic night. Our comparison between these callows and previously preserved specimens indicated a posteclosion age of between 5-8 days.

Larval size: Several hundred larvae were collected by aspiration from the first emigration. By visual inspection, we separated the 10 largest and 10 smallest larvae and measured them with the aid of a dissecting microscope fitted with an ocular micrometer. The mean length of the large group was $4.0 \mathrm{~mm}$ (range $=3.8-4.2 \mathrm{~mm}$ ), as compared with a mean of $1.5 \mathrm{~mm}$ (range $=1.3-1.7 \mathrm{~mm}$ ) for the small group. When these data are compared with Mirenda and Topoff's (1980) graph of larval growth versus nomadic day, they correspond to a range of nomadic days between 4-6.

The nightly patterns of activity for colony no. 2 and for the control colony are summarized in Table 2 . For this small colony, we 


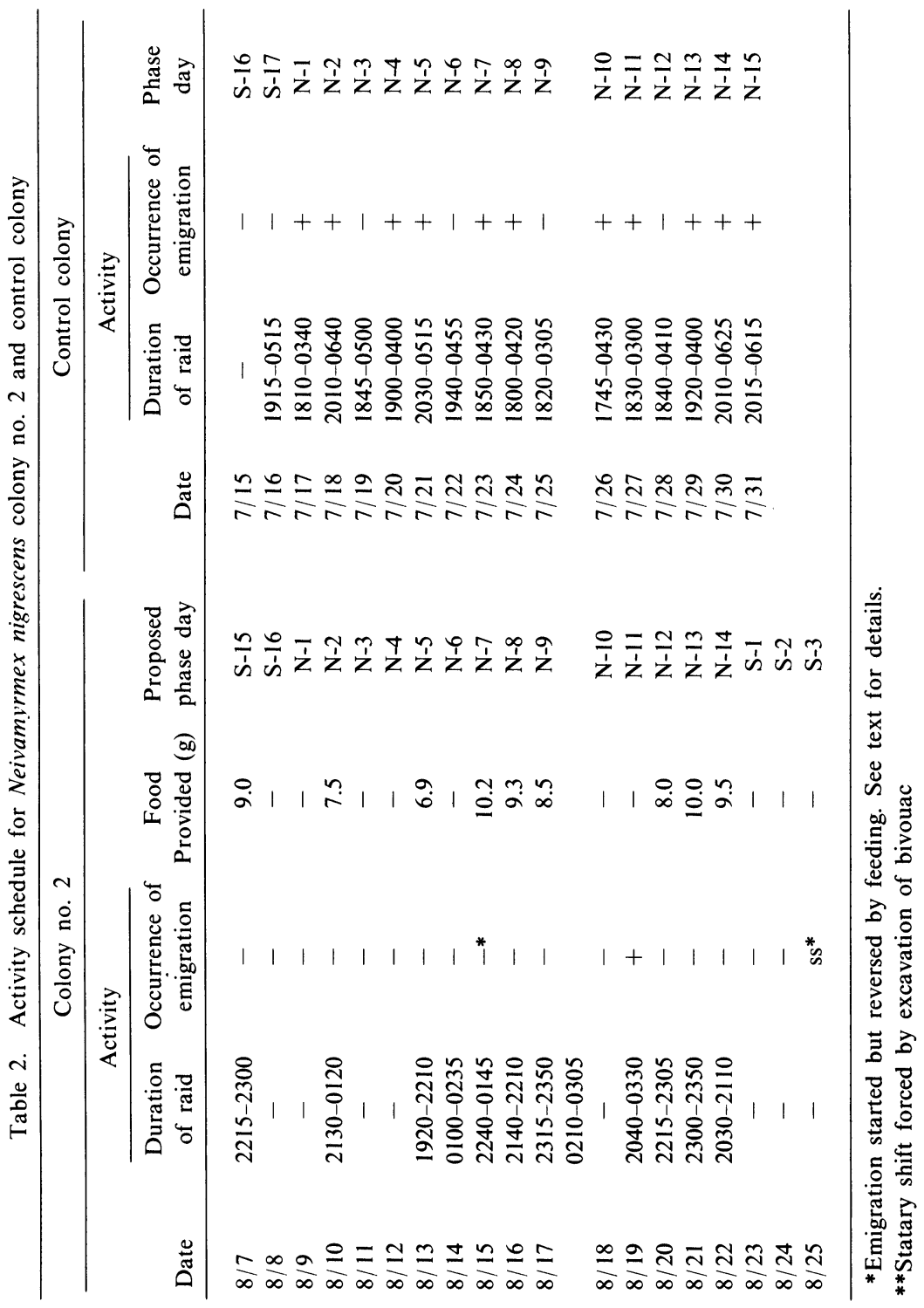


were able to monitor the time of onset and the duration of each night's raid, in addition to the emigration frequency. This colony was released from a laboratory nest at $1900 \mathrm{hr}$ on August 7 . Because this was statary day 15 , most of the pupae were fully pigmented. The colony promptly moved into a subterranean nest beneath a small hole in the desert floor. The first raiding column appeared shortly after $2200 \mathrm{hr}$, at which time $9.0 \mathrm{~g}$ of Novomessor brood and termites were placed near the raiding front. The army ants removed the booty in less than $1 \mathrm{hr}$, after which all surface activity ceased. For the next seven nights, the colony was either not active on the surface or, at best, conducted brief raids (each of which was immediately followed by artificial feeding) but no emigrations. On August 15 we arrived at the study site after $2200 \mathrm{hr}$, and found the colony emigrating $25 \mathrm{~m}$ to the NW. Because previously-collected food was being transported to the new nest, but no larvae had yet appeared, we considered the emigration to be in an early stage. Accordingly, 10.2 grams of booty were placed near the emigration column, $1 \mathrm{~m}$ from the old bivouac. This resulted in recruitment of ants both from the short column leading to the old nest, and from the longer emigration column. All of the artificially-placed food was taken back to the old nest, and the emigration was aborted.

On August 19 (nomadic day 11), after 2 days of not having been fed, the colony conducted its only successful emigration. The move took the colony $19 \mathrm{~m}$ to the $\mathrm{N}$, beneath an Ephedra bush. On August 25, we excavated the colony and forced it to shift its statary bivouac. This procedure verified that the colony's larvae had pupated. Thus, throughout a nomadic phase lasting 14 days, the colony conducted only one completed emigration. On 4 nomadic nights no raiding occurred. During the 10 nights in which raiding took place, the median time for raid onset was $2200 \mathrm{hr}$, and the median duration of each raid was $1.5 \mathrm{hr}$.

The control colony, which was also released from the laboratory at the end of a statary phase, exhibited more typical patterns of nomadic behavior (Table 2). During a 15-day nomadic phase, the colony emigrated on 11 nights. Some degree of raiding took place on every nomadic night. The median time of raid onset for the control colony was $1850 \mathrm{hr}$, and the median duration of raiding was $9.7 \mathrm{hr}$. 


\section{Discussion}

Much of the discussion generated by Schneirla's brood-stimulation theory concerns the relative degree to which raiding and emigrations are influenced by interactions between brood and adults (internal processes), and by external environmental factors. Theoretical support for emphasizing brood-related processes stems not only from Schneirla's own research with army ants (Schneirla, 1957, 1958, 1971), but from studies of other social insects as well. For example, honeybee workers can collect protein-rich pollen or carbohydrate-rich nectar. Louveaux (1950) found that the amount of pollen collected by an incipient colony is small, but increases as the brood population increases. In another experiment (Louveaux, 1958), he removed the colony queen from a mature colony and found that pollen collection was unaffected until many of the larvae had pupated. Further evidence of larval stimulation of adult foraging came from Fukuda, 1960 (in Free, 1967), who showed that foraging workers from a recently-divided colony collected very little pollen until the eggs laid by the new queen hatched into larvae. Finally, Free (1967) demonstrated that adult worker foraging was influenced more by direct access to the brood than by brood odor alone. Perhaps most significant was the additional finding that artificially feeding a colony with pollen resulted in a decrease in pollen collection and a corresponding increase in nectar collection.

Although Schneirla was primarily concerned with the role of callow and larval excitation, he did recognize the role of food as an ecological parameter. Thus, at an early stage of his field research with the neotropical genus Eciton, he reported (Schneirla, 1938) that colonies frequently emigrate along the heaviest raiding route of that day. Nevertheless, it was Rettenmeyer (1963) who first suggested that the location and amount of captured food might influence not only the path of colony movements, but the very tendency to emigrate in the first place. The idea that colony excitation could be related to brood satiation has received empirical support from Free's (1967) study of honeybees and from related research with the myrmicine ant genus Myrmica (Brian, 1957, 1962; Brian and Abbott, 1977; Brian and Hibble, 1963). It was therefore significant that by the time of Schneirla's last field study, concerning emigration behavior in the paleotropical army ant genus Aenictus, he conceded that short-term variations in colony excitation may 
depend upon the "alimentary condition prevalent in the brood" (Schneirla and Reyes, 1969), and that emigrations are likely to begin soon after food has run low.

In a recent series of field and laboratory studies of nomadic behavior in nearctic colonies of $N$. nigrescens (Topoff and Mirenda, 1980 a,b; Mirenda et al., in press), we demonstrated: (1) that the location of booty clearly influences the direction of raiding and therefore of emigrations; and (2) that artificially-fed colonies exhibit a lower frequency of emigrations. The present study differs from these in that food augmentation began late in the statary phase, before most of the callow population had eclosed. In addition to delaying the onset of the nomadic phase by reducing excitation from newly-eclosed callows (Topoff et al., 1980a), this was our first attempt to eliminate emigrations through a complete nomadic phase in the field.

During the six days of food augmentation for colony no. 1, we provided a total of $144 \mathrm{~g}$ of booty. Since the colony generated few additional raiding columns, the artificially-administered booty represents over $90 \%$ of the colony's total food intake for that period. According to Mirenda et al. (1980), colonies of $N$. nigrescens gather approximately $0.4 \mathrm{mg}$ of booty/larva/nomadic night. Thus, on the average, we provided colony no. 1 each night with an amount of food that would be collected by a colony containing about 60,000 larvae. Although our estimate of colony size contains an error of \pm $20 \%$, we can be reasonably certain of having provided this colony with about 1.2 times the amount of food it would normally gather. Although the large size of this colony dictated that we could no longer supplement its food to the same degree throughout the remainder of the nomadic phase, the evidence from phase length, callow pigmentation, and larval size supports the conclusion that the onset of the nomadic phase was delayed for 4-8 days.

For colony no. 2 , which was considerably smaller and more precisely counted, intensive overfeeding was more feasible. On the average, $8.8 \mathrm{~g}$ of booty were provided on food-supplemented nights. This is more than 5 times the amount of food that a colony of this size would collect in the field. In view of this feeding regime, it is not surprising that the colony conducted only one completed emigration throughout its 14-day nomadic phase. We must emphasize, however, that a reduction of the frequency of nomadic emigrations is by itself not sufficient to infer a relationship between food supply and 
colony arousal. In all of our laboratory and field studies, we always placed food near raiding fronts, within a few meters of the bivouac. In most cases, the army ants established few or even no additional raid columns beyond the artificial feeding site. Thus, our feeding procedure reduces the ability of the ants to locate a suitable nesting site, which is a prerequisite for a successful emigration (Mirenda et al., in press). The case for a relationship between food supply and colony arousal is made considerably stronger by considering, in addition to emigration frequency, the temporal aspects of the ants' raiding behavior. Colony no. 2 conducted no raids on 4 nomadic nights. By comparison, the complete absence of raiding (on stormless nights) for a nomadic colony of $N$. nigrescens has never been reported, although it is a common occurrence for statary colonies. Finally, when we include the data on raid onset and duration for colony no. 2, we conclude that overfeeding can effectively shift the level of overall colony activity from a nomadic to a statary condition.

\section{ACKNOWLEDGMENTS}

The base of operations for this study was the Southwestern Research Station of The American Museum of Natural History. This research was supported by NSF Grant BNS-8004565, and by PSC-CUNY Grant 13492.

\section{Literature Cited}

BRIAN, M. V.

1957. Food distribution and larval size in cultures of the ant Myrmica rubra L. Physiol. Comp. Oecol. 4: 329-345.

Brian, M. V. and A. Abbott

1977. The control of food flow in a society of the ant Myrmica rubra L. Anim. Behav. 25: 1047-1055.

Brian, M. V. AND J. HibBle

1963. Larval size and influence of the queen on growth in Myrmica. Insectes Soc. 10: 71-81.

FREE, J. B.

1967. Factors determining the collection of pollen by honeybee foragers. Anim. Behav. 15: 134-144.

Louveaux, J.

1950. Observations sur le déterminisme de la récolte du pollen par les colonies d'abeilles. C.R. Acad. Sci., Paris 231: 921-922.

1958. Recherches sur la récolte du pollen par les abeilles (Apis mellifica L.) Ann. Abeille 1: 113-188, 197-221. 
MiRENDA, J. AND H. TOPOFF

1980. Nomadic hehavior by ants in a desert-grassland habitat. Behav. Ecol. Sociobiol. 7: 129-135.

Mirenda, J., D. Eakins, K. Gravelle, and H. Topoff

1980. Predatory behavior and prey selection by army ants in a desert-grassland habitat. Behav. Ecol. Sociobiol. 7: 119-127.

Mirenda, J., D. Eakins, and H. TopofF

in press. Relationship between raiding and emigration in the nearctic army ant Neivamyrmex nigrescens. Insectes Soc.

RETTENMEYER, C. W.

1963. Behavioral studies of army ants. Univ. Kansas. Sci. Bull. 44: 281-465.

SChNeirla, T. C.

1938. A theory of army ant behavior based on the analysis of activities in a representative species. J. Comp. Psychol. 25: 51-90.

1957. Theoretical considerations of cyclic processes in doryline ants. Proc. Amer. Phil. Soc. 101: 106-133.

1958. The behavior and biology of certain nearctic army ants: last part of the functional season, southeastern Arizona. Insectes Soc. 5: 215-255.

1971. Army ants: a study in social organization. Freeman, Calif. 349 p.

SChNeIRla, T. C. AND R. Z. Brown

1950. Army-ant life and behavior under dry-season conditions. 4. Further investigations of the cyclic processes in behavioral and reporductive functions. Bull. Amer. Mus. Nat. Hist. 95: 265-353.

Schneirla, T. C. AND A. Y. Reyes

1969. Emigrations and related behavior in two surface-adapted species of the Old World doryline ant, Aenictus. Anim. Behav. 17: 87-103.

TOPOFF, H. AND J. Mirenda

1980a. Army ants on the move: relationship between food supply and emigration frequency. Science 207: 1099-1100.

1980b. Army ants do not eat and run: relationship food supply and emigration behaviour in Neivamyrmex nigrescens. Anim. Behav. 28: 1040-1045.

Topoff, H., J. Mirenda, R. Droual, and S. Herrick

1980a. Onset of the nomadic phase in the army ant Neivamyrmex nigrescens: distinguishing between callow and larval excitation by brood substitution. Insectes Soc. 27: 175-179.

1980b. Behavioural ecology of mass recruitment in the army ant Neivamyrmex nigrescens. Anim. Behav. 28: 779-789. 

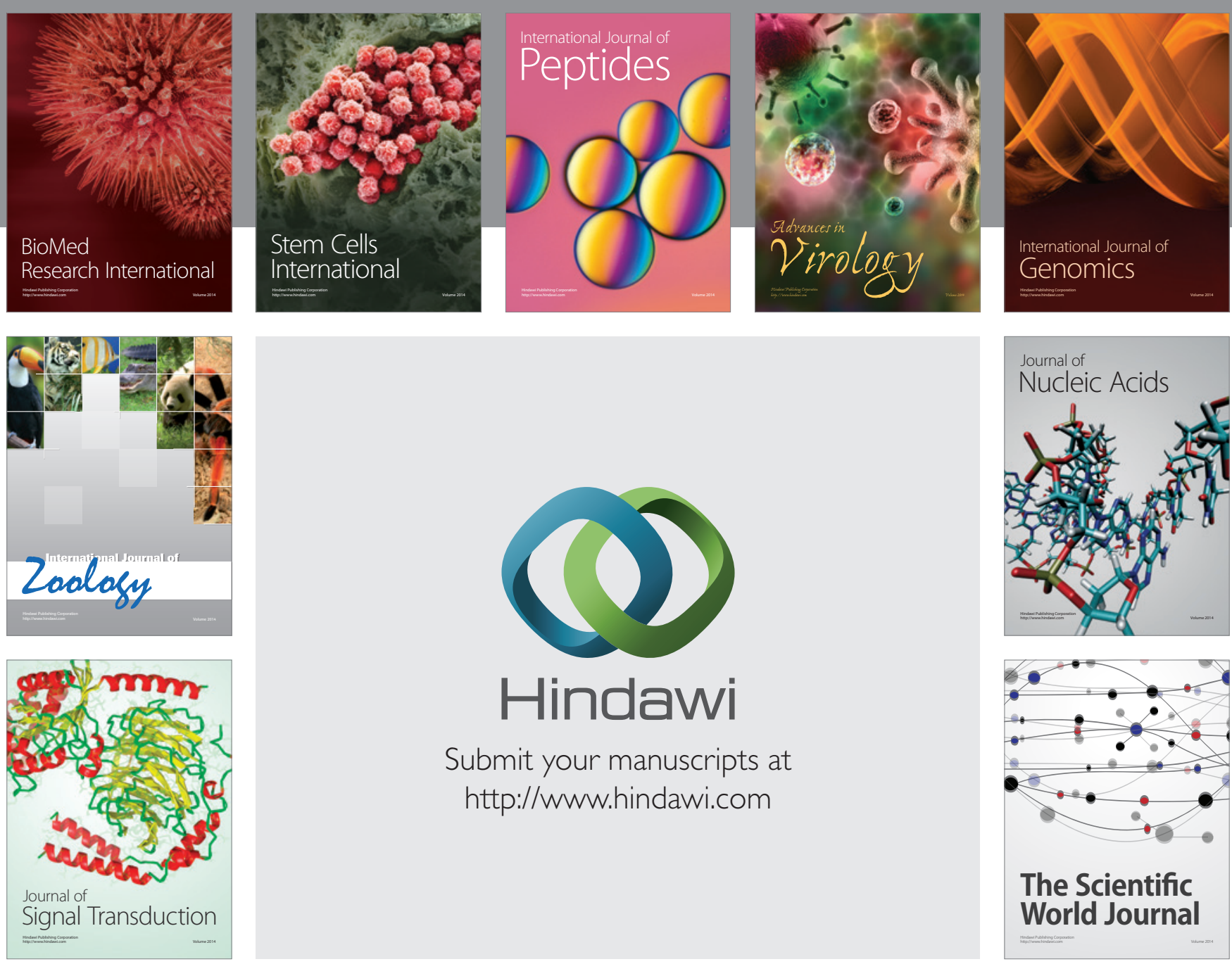

Submit your manuscripts at

http://www.hindawi.com
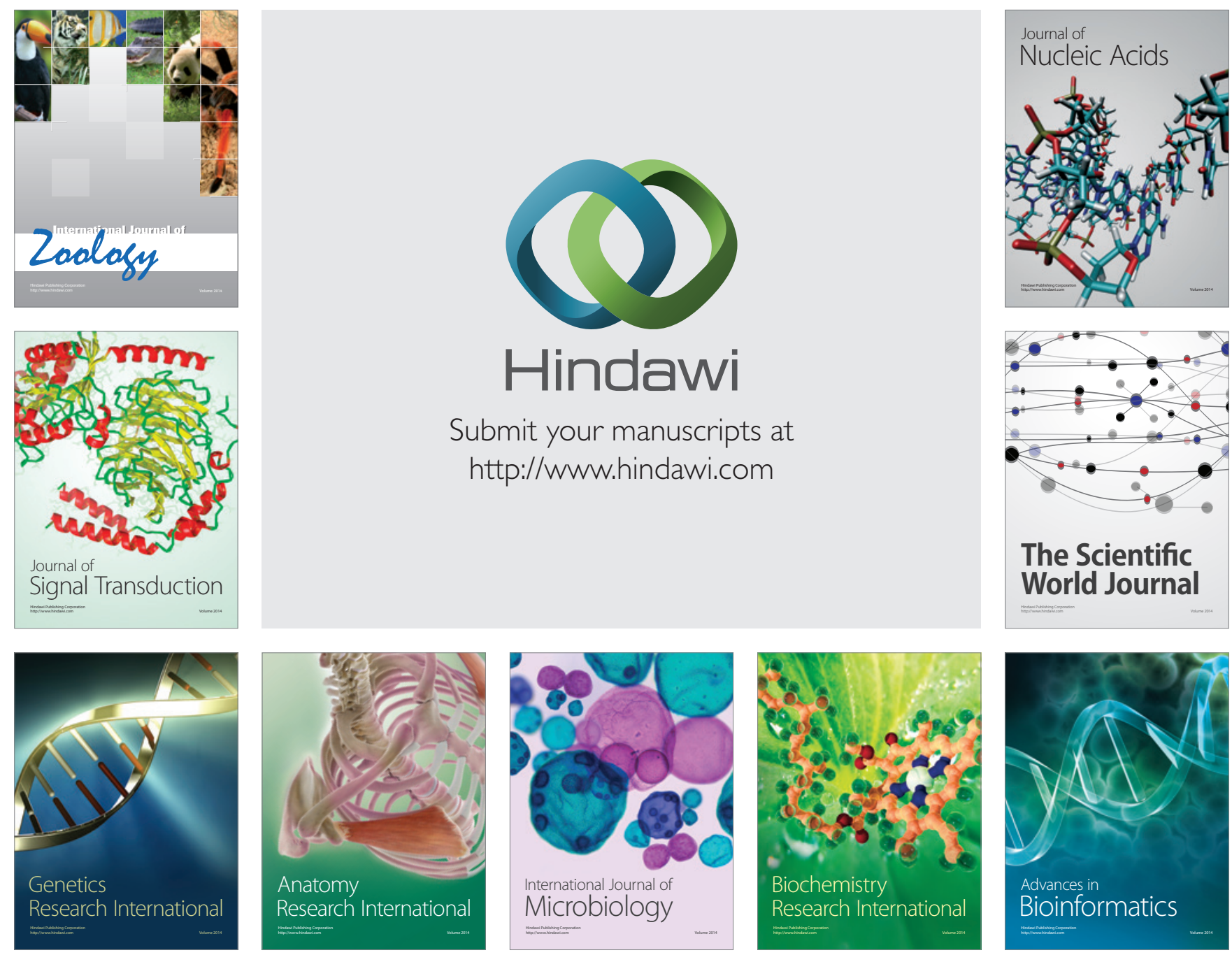

The Scientific World Journal
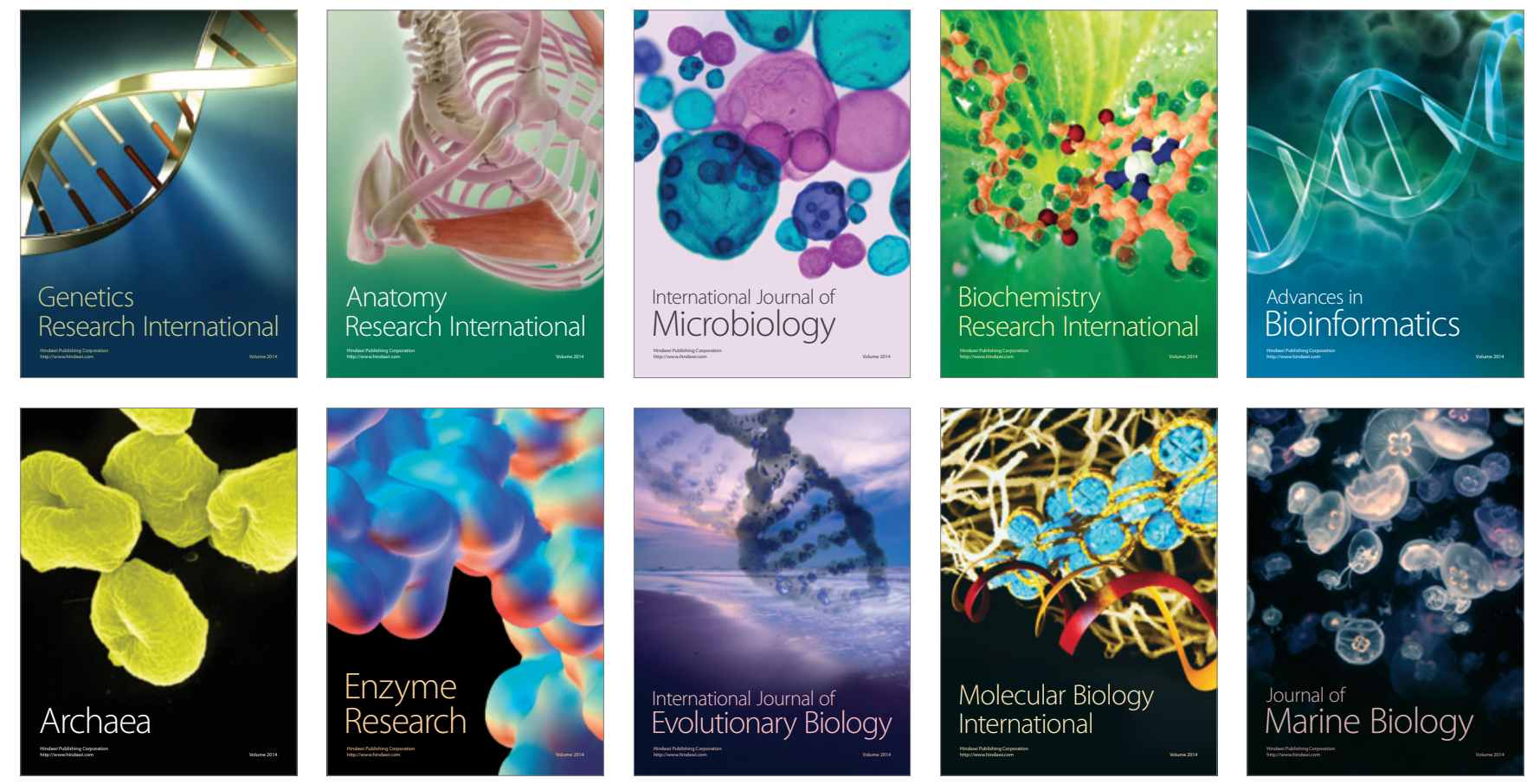